\title{
Impact of guidewire selection and operator expertise on radiation exposure in transradial angiography
}

\author{
Jianmin Yang ${ }^{1,2}$, Ningfu Wang ${ }^{2}$, Xiaoshan Tong ${ }^{2}$, Xianhua Ye ${ }^{2}$, Liang Zhou' ${ }^{2}$, Guoxin Tong ${ }^{2}$, Yun Shen ${ }^{2}$
} and Shuzheng LV ${ }^{1 *}$

\begin{abstract}
Background: Several studies have implied that the time of radiation exposure for patients and operators during the transradial approach for coronary angiography (TRA) is associated with the use of different guidewire or catheter and operator's finesse. This study aimed to assess the effects of non-hydrophilic or hydrophilic guidewire and operator expertise on fluoroscopy time and procedure time of TRA and further effects on the procedure safety.

Methods: A total of 1035 consecutive patients undergoing TRA were recruited prospectively and respectively divided into non-hydrophilic guidewire and hydrophilic guidewire group, or well-experienced group and less-experienced group. The primary endpoints were fluoroscopy time and procedure time. Secondary endpoints included contrast volume, cost, guidewire exchange, switchover and complications.

Results: TRA by non-hydrophilic guidewire group showed shorter fluoroscopy time and procedure time compared with hydrophilic guidewire group, similar results were found between well-experienced group and less-experienced group. Moreover, using of non-hydrophilic guidewire significantly reduced the incidence of hematoma and abnormal guidewie advancement, well-experienced group showed less dosage of contrast volume, lower incidence of radial artery spasm and frequency of guidewire exchange.

Conclusions: TRA by non-hydrophilic guidewire and well-experienced operator can decrease radiation exposure of patients and operators through reducing the fluoroscopy time and procedure time and further increase procedure safety. These will contribute to the optimization of TRA procedure and promote its widely application.
\end{abstract}

Keywords: Coronary angiography, Transradial approach, Fluoroscopy time, Procedure time

\section{Background}

The transradial approach for coronary angiography (TRA) has gained popularity due to decreased access site bleeding complications, increased patient comfort, earlier mobilization, lower costs and mortality rate than trans femoral angiography (TFA) [1-5]. However, TRA under fluoroscopic guidance exposes both the patient and operator to variable amounts of radiation [6]. It has been reported that the dose of radiation exposure depends on the duration of the procedure, operator technique, and that adverse side effects of prolonged fluoroscopic procedures

\footnotetext{
*Correspondence: shuzhenglv0829@163.com

'Department of Cardiology, Beijing Anzhen Hospital, Capital Medical University, No.2, Anzhen Road, Beijing 100029, China

Full list of author information is available at the end of the article
}

and increased radiation exposure over time include dermatologic burns for the patient and increased risk of malignancy to both patients and operators [7-11]. Therefore, paying efforts to minimize radiation exposure is of paramount importance.

Many studies have found that the difficult advancement of guidewire or catheter, and the change in manipulation of the catheters caused by the greater difficulty in cannulating the artery, the possibility of spasm, anatomical variations in the arteries of the upper limb, could prolong procedure time and fluoroscopy time [6,12-14]. Previous study found that using of a hydrophilic coated guidewire and a new hydrophilic-coated guiding catheter could facilitate the advancement with the access problems caused by radioulnar loops and/or severe arterial tortuosity [15]. 
Zhao et al. found that compared with hydrophilic coated guidewire, the successful use of PTCA guidewire followed with passage of diagnostic catheter resulted in straightening of the radial artery loop or radial artery tortuosity. These may provide evidence that the optimization of guidewire or catheter can reduce the complications of TRA. However, the previous studies have not further focused on the effects of the improvements in guidewire or catheter on the fluoroscopy time and procedure time. Meanwhile, the operator expertise has been reported to be related to the reduction of procedure time and radiation exposure [14], but there is still controversy on this view $[6,12]$.

Therefore, in the present study, the non-hydrophilic and hydrophilic guidewire were employed in TRA to assess the effects on the procedure time and fluoroscopy time. Moreover, the effects of operator expertise in TRA were also investigated. Hopefully, the results would provide valuable reference for the optimization of TRA.

\section{Methods}

\section{Study design and populations}

This prospective observational study was conducted during the period of October, 2012 to October, 2013. A total of 1057 consecutive patients were initially included for diagnostic coronary angiography. The patients were excluded if they had radial artery hypoplasia, acute coronary syndrome, untreated infection, severe anaemia, severe electrolyte imbalance, severe active bleeding, acute renal failure, acute pulmonary edema, heart shock. All patients who underwent the Allen's test [16] were with positive results. At last, 22 cases conducted by left radial artery or femora artery because of failure in puncture were excluded and a total of 1035 cases were enrolled. The patients were divided into non-hydrophilic guidewire group (518) and hydrophilic guidewire group (517) according to the order interval, well-experienced group (716) and lessexperienced group (319) by randomly. The study project was assessed and approved by the ethics committee of Beijing Anzhen Hospital and informed consent was obtained from each patient.

\section{Procedures}

\section{Right radial artery puncture}

With the wrist in hyperextension position, the right radial artery was punctured using a 21 gauge needle (Terumo Co., Japan) after induction of local anesthesia with $1 \%$ xylocaine. Other proper puncture techniques were also available based on operator preference. A 6French $(F)$ sheath (length, $11 \mathrm{~cm}$ ) was advanced over a 0.025-inch guidewire (Terumo Co., Japan). All patients received 3000 units of heparin through the introducer side-port. Medication of a cocktail of nitrate $(200 \mu \mathrm{g})$ and verapamil $(2 \mathrm{mg})$ to prevent spasm was infused into the radial artery.

\section{TRA by non-hydrophilic or hydrophilic guidewire}

Coronary angiography was performed using Judkins Right $5 \mathrm{~F}$ catheters. Catheter was inserted over a 0.035 -inch (length, $150 \mathrm{~cm}$ ) non-hydrophilic J-tipped guidewire (Cordis Co., USA) and firstly carefully advanced into the subclavian artery without fluoroscopy, then was advanced to coronary sinus under fluoroscopy. After careful aspiration of bubbles and debris with appropriate flushing, the catheter was inserted into the right coronary ostium, and then medium contrast was manually injected using a $10 \mathrm{ml}$ syringe connected to catheter. After right coronary artery angiography, the guidewire was introduced into the coronary sinus again and used for catheter exchange without fluoroscopy to perform left coronary artery angiography. In case of difficult advancement of the non-hydrophilic guidewire, a retrograde angiogram was performed to identify the problem, such as loops or other anatomic variants. Based on the angiogram and under fluoroscopic guidance, guidewire and catheter were adjusted to advance, if failed, a second attempt was made with a hydrophilic-coated guidewire (Terumo.Co, Japan), In case of failure with this guidewire or serious complications occurred, the other access was selected to complete angiography. TRA by hydrophilic guidewire was performed similar to the above description, but the advancement of hydrophilic guidewire was all under fluoroscopy.

After angiography, catheters were removed over a guidewire to prevent spasm of the artery and to reduce the possibility of intimal damage. At the end of the procedure, wound haemostasis was achieved by local compression using a compress device (Terumo Co., Japan). The haemostasis device was removed 6 hours later. The adhoc or a separate angioplasty was performed as scheduled.

\section{Data collection}

Fluoroscopy time which was recorded as a surrogate of radiation exposure and procedure time were the primary endpoints, and the secondary endpoints were as following: contrast volume, cost, guidewire exchange, switchover, radial arteries spasm, hematoma, compartment syndrome, pseudoaneurysm, arterio-venous fistula, stroke.

\section{Definitions}

Well-experienced operator was considered as who had performed $>500$ TRA including $>200$ procedures in a recent year. The operator who had performed 200-500 TRA including $<200$ procedures in a recent year was considered as less experienced. Fluoroscopy time was recorded as the total time needed fluoroscopy during the angiography procedure. Procedure time was recorded as the interval between administration of lidocaine and the finish of angiography. Radial arteries spasm was determined by addressing 5 signs: persistent forearm pain, 
pain response to catheter manipulation, pain response to sheath withdrawal, difficult catheter manipulation after being "trapped" by the radial artery, and considerable resistance to withdrawal of sheath. Radial arteries spasm was defined as at least 2 of the 5 signs [17]. Guidewire exchange was calculated as the need to change from non-hydrophilic to hydrophilic guidewire or vice versa. The definition of switchover was the need to puncture another access site due to any procedural failure after inserting the sheath.

\section{Statistical analysis}

All analyses were performed with the SPSS 17.0 statistical package (Chicago IL, USA). The distribution of continuous data was determined using the 1-sample KolmogorovSmirnov test. Normally distributed data (presented as mean \pm standard deviation), and non-parametric data (as median and min-max) were compared using the Student's $t$ test and Mann-Whitney $U$ test respectively. Categorical variables were expressed as frequency percentages and by chi-square statistics. $P<0.05$ was considered as statistically significant.

\section{Results}

\section{Patients characteristics}

The baseline demographic features were detailed in Table 1 , and that significant difference was not observed among groups.

\section{Primary endpoints}

As the results showed,fluoroscopy time and procedure time were significantly shorter in non-hydrophilic guidewire group than those in hydrophilic guidewire group (3.8 [2.7-10.8] minutes vs. 4.3 [3.1-13.7] minutes; 19.2 [9-35] minutes vs. 21.2 [16-36] minutes, $P<0.001$, respectively). Similarly, well-experienced group had shorter fluoroscopy time and procedure time than less-experienced group (3.9 [2.7-8.5] minutes vs. 4.2 [3.1-13.7] minutes; 19.7 [9-36] minutes vs. $21.3[14-35]$ minutes, $P<0.001$, respectively) (Figures 1 and 2).

\section{Secondary endpoints}

As shown in the Table 2, compared with the hydrophilic guidewire group, TRA by non-hydrophilic guidewire significantly reduced the incidence of hematoma $(P<0.05)$ and abnormal guidewire advancement $(P<0.05)$, and that resulted in a relatively lower cost $(P<0.001)$, but more chances of guidewire exchange were observed in non-hydrophilic guidewire group. In addition, there were no significant differences in contrast volume, switchover, radial artery spasm and bleeding between two groups. Compared with well-experienced group, less-experienced group showed more dosage of contrast volume $(P<0.001)$, higher incidence of radial artery spasm $(P<0.05)$ and frequency of guidewire exchange. There were no statistically significant differences in cost, switchover, abnormal guidewire advancement, hematoma and bleeding between two groups. Stroke and other complications were not observed in two groups respectively.

\section{Discussion}

Currently, increasing measures attempt to decrease the radiation exposure include using of lead apron, keeping a maximum distance from the $\mathrm{X}$-ray source and minimization of the field of view, but all do not significantly reduce the risk of radiation exposure and procedure time [18]. The feasible way is to improve the equipment of procedure. Previous studies have suggested that the time of radiation exposure for patients and operators is associated with the use of different guidewire or catheter and operator's finesse $[14,15,19]$. Thus, in this study, we assessed clinical differences of TRA conducted by non-hydrophilic and hydrophilic guidewire on fluoroscopy time and procedure time. The results indicated that TRA by non-hydrophilic guidewire decreased fluoroscopy time and procedure time, and increased the procedure safety and cost-effectiveness. The further assessment of the operator expertise confirmed that TRA conducted by well-experienced operator decreased fluoroscopy time and procedure time, and increased the procedure safety.

Fluoroscopy time was recorded as a surrogate of radiation exposure and evaluated in this study. The results

Table 1 Baseline demographic characteristics among groups

\begin{tabular}{|c|c|c|c|c|c|c|}
\hline$>$ & $\begin{array}{l}\text { Non-hydrophilic } \\
(n=518)\end{array}$ & $\begin{array}{l}\text { Hydrophilic } \\
(n=517)\end{array}$ & $P$ value & $\begin{array}{l}\text { Well-experienced } \\
(n=716)\end{array}$ & $\begin{array}{l}\text { Less-experienced } \\
(\mathrm{n}=319)\end{array}$ & $P$ value \\
\hline Age, years & $66.15 \pm 10.58$ & $65.86 \pm 10.93$ & 0.665 & $66.20 \pm 10.92$ & $65.58 \pm 10.36$ & 0.397 \\
\hline Male, n (\%) & $287(55.4)$ & $300(58)$ & 0.415 & $413(57.7)$ & $174(54.5)$ & 0.377 \\
\hline Hypertension, n (\%) & $349(67.4)$ & $347(67.1)$ & 0.947 & $489(68.3)$ & $207(64.9)$ & 0.283 \\
\hline Diabetes, n (\%) & $137(26.4)$ & $133(25.7)$ & 0.832 & $198(27.7)$ & $72(22.6)$ & 0.092 \\
\hline Hyperlipemia, n (\%) & $78(15.1)$ & $80(15.5)$ & 0.863 & $116(16.2)$ & $42(13.2)$ & 0.225 \\
\hline Smoking, n (\%) & 167 (32.2) & $163(31.5)$ & 0.841 & 219 (30.6) & $111(34.8)$ & 0.18 \\
\hline
\end{tabular}




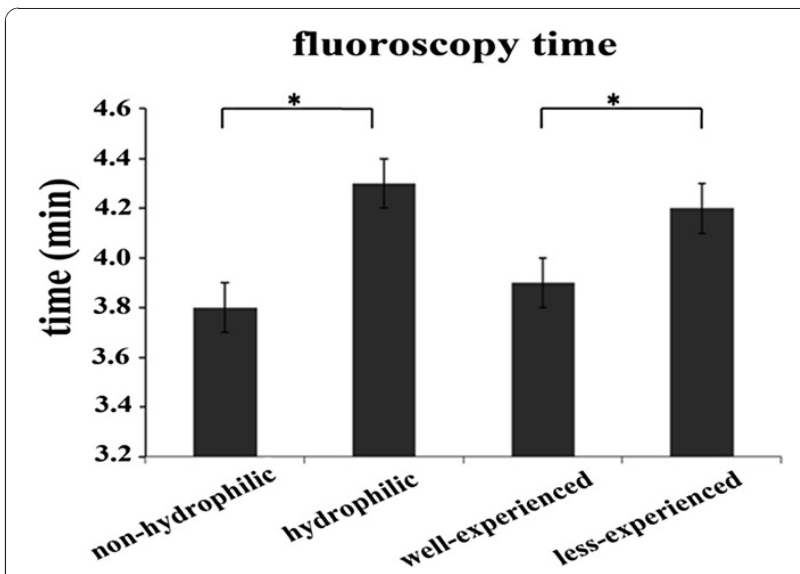

Figure 1 The effects of different guidewires and operator experience on fluoroscopy time in TRA. *indicated a significant difference between two groups $(P<0.001)$.

displayed that TRA by non-hydrophilic guidewire exhibited a significantly shorter fluoroscopy time than TRA by hydrophilic guidewire. The possible explanation is that fluoroscopy is needed in advancement of the hydrophilic guidewire and catheter exchange because they prefer to perforate the small artery [16], while nonhydrophilic guidewire could be manipulated without fluoroscopy, except in case of difficult advancement of guidewire. These results indicated that TRA by nonhydrophilic guidewire was likely to reduce the radiation exposure of operators and patients and further to alleviate the adverse effects caused by radiation exposure. Meanwhile, in non-hydrophilic guidewire group, the procedure time was notably shorter than that in hydrophilic guidewire group. Similar to the PTCA guidewire [19], the using of non-hydrophilic guidewire might contribute to the advancement of the catheter through the radial artery loop. Moreover, the support power is stronger

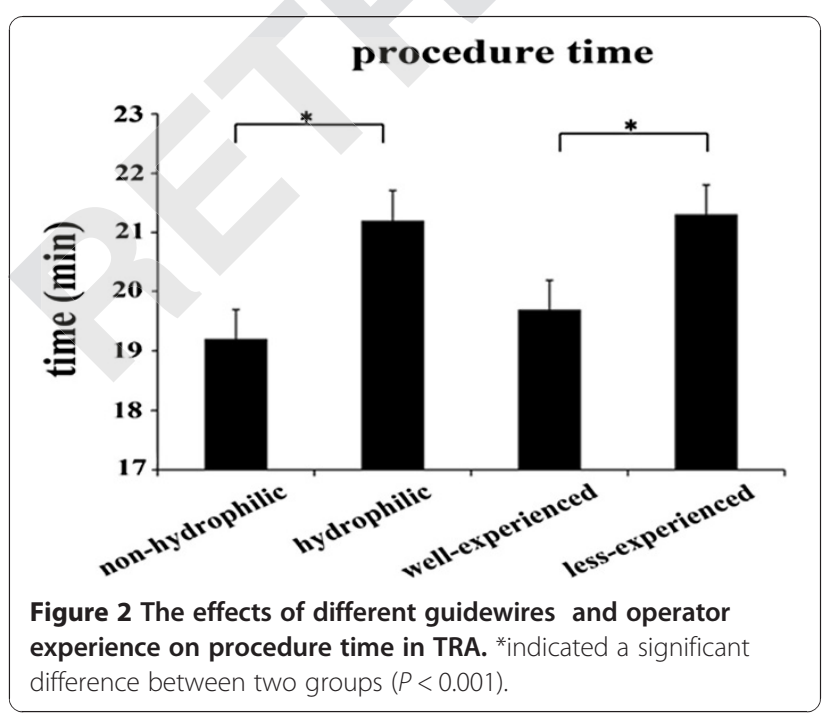

in non-hydrophilic guidewire, which may also conduce to the catheter passing the tortuosity and inserting into the coronary ostium quickly. These highlighted the suitability of non-hydrophilic guidewire was superior to the hydrophilic guidewire in TRA. The potential advantages of nonhydrophilic guidewire on reducing the radiation exposure are promising for the optimization of TRA.

Given that the increased difficulty in catheter manipulation in TRA due to anatomical variations of arterial results in a long learning curve for operators [20], therefore, the operator's experience is suspected to be highly important for the success rate of TRA. However, whether experienced operators can decrease fluoroscopy time and procedure time is still in controversy $[6,14]$. The results in this study demonstrated that TRA by well-experienced operators could decrease fluoroscopy time and procedure time compared with less-experienced operators. A probable explanation is that the skills of well-experienced operators in manipulating the catheters expertly result in less frequency of guidewire exchange. These results indicate operator expertise plays an essential role in time needed for integral procedure, especially for fluoroscopy time. These further imply that the organized and more effective experience training is very necessary for promoting the experience of operators in TRA.

Radial artery spasm and hematoma are the most common complications of TRA, which cause significant discomfort and reduce the procedural success rate although they are usually not serious $[21,22]$. The incidence of radial artery spasm in this study was $6.47 \%$, which was lower than the results of early studies but similar to the data of recent clinical research [23-26]. We further investigated the effects of different guidewire and operator expertise on radial artery spasm and hematoma. Though hydrophilic guidewire could reduce the friction between guidewire and vessel, no significant difference of the spasm incidence was observed between two groups, which might be due to that the friction was mainly between catheters and vessel and not between the guidewire and vessel. These results, to some extent, provided evidence for the previous findings that hydrophiliccoated catheter could reduce the incidence of spasm [27]. However, compared with non-hydrophilic guidewire, a higher incidence of hematoma was observed in hydrophilic group even though the advancement of guidewire was under fluoroscopy. It further demonstrated that the using of non-hydrophilic guidewire significantly reduced the complications of TRA and increased the procedure safety. Moreover, an obvious reduction of radial artery spasm was observed in well-experienced operators, which might be due to a high success rate of first puncture attempt in well-experienced operators group [26]. Although significant statistical difference was not found in the incidence of hematoma between two groups, a 
Table 2 Procedural characteristics among groups

\begin{tabular}{|c|c|c|c|c|c|c|}
\hline & $\begin{array}{l}\text { Non-hydrophilic } \\
(n=518)\end{array}$ & $\begin{array}{l}\text { Hydrophilic } \\
(n=517)\end{array}$ & $P$ value & $\begin{array}{l}\text { Well-experienced } \\
(n=716)\end{array}$ & $\begin{array}{l}\text { Less-experienced } \\
(\mathrm{n}=319)\end{array}$ & $P$ value \\
\hline Contrast volume, $\mathrm{ml}$ & $72.12 \pm 11.45$ & $72.51 \pm 11.23$ & 0.579 & $71.48 \pm 11.17$ & $74.19 \pm 11.51$ & $<0.001$ \\
\hline Cost, yuan & $1316[1287,2353]$ & $1443[1427,1928]$ & $<0.001$ & $1375[1287,2344]$ & $1388[1287,2353]$ & 0.124 \\
\hline Guidewire exchange, n (\%) & $22(4.2)$ & $3(0.6)$ & $<0.001$ & $13(1.8)$ & $12(3.8)$ & 0.027 \\
\hline Switchover, n (\%) & $18(3.5)$ & $16(3.1)$ & 0.455 & $20(2.5)$ & $14(4.3)$ & 0.542 \\
\hline Radial artery spasm, n (\%) & $36(6.9)$ & $31(6.0)$ & 0.614 & $38(5.3)$ & $29(9.1)$ & 0.028 \\
\hline Hematoma, n (\%) & $16(3.1)$ & $30(5.8)$ & 0.036 & $27(3.8)$ & $19(6)$ & 0.141 \\
\hline Bleeding, n (\%) & $21(4.1)$ & $30(5.8)$ & 0.2 & $33(4.6)$ & $18(5.6)$ & 0.534 \\
\hline Guidewire advance into other vessel, n (\%) & $1(0.2)$ & $13(2.5)$ & 0.001 & $9(1.3)$ & $5(1.6)$ & 0.772 \\
\hline Other complications, n (\%) & 0 & 0 & 1 & 0 & 0 & 1 \\
\hline
\end{tabular}

reduction trend was obviously observed. Further investigation is necessary to confirm it.

In the current study, for the purpose of reducing the other potential confounding variables, the characteristics of patients were generally well-balanced between the groups. Additionally, the default approach for the radial operators in the current study was the right radial artery. The main reason is that the right radial artery is routinely used in clinical practice due to feasibility with room setup and familiarity of manipulating the catheter from the right side as in the femoral approach. Although it has been reported that for coronary diagnostic procedures, left radial approach (LRA) is associated with lower fluoroscopy time and radiation dose adsorbed by patients compared with the right radial approach (RRA) [28-31], nevertheless, leaning over the patient to manipulate catheters through the left radial artery may be uncomfortable and cause back strain for operators [32]. However, there are some limitations in the present study. Higher chances of guidewire exchange were observed in non-hydrophilic group because of severe tortuosity, which might prolong the fluoroscopy time and procedure time in these patients, but guidewire exchange was commonly rare except those accompanied by switchover. Even taking the guidewire exchange into account, the cost in non-hydrophilic group was still lower than that in hydrophilic guidewire group. Furthermore, hydrophilic guidewire had more chances advanced into coronary artery and carotid artery due to the inherent characteristic of hydrophilic guidewire. Though no adverse events happened in the study, it was a potential danger for the incidences of coronary dissection, acute myocardial infarction and stroke. Owing to the limited candidate patients in this study, the above results need further investigation in multiple centers and larger samples. Furthermore, the combined effects of TRA by nonhydrophilic guidewire and performed by operator expert are not investigated in this study and hence further studies are still necessary.

\section{Conclusions}

TRA by non-hydrophilic guidewire other than by hydrophilic guidewire and performed by operator expert may become the default strategy because of its advantages with shorter radiation exposure, lower costs and better safety. These will contribute to the optimization of TRA procedure and promote the widely application and acceptance of TRA.

\section{Highlights}

1. A total of 1035 consecutive patients undergoing TRA were recruited.

2. TRA by non-hydrophilic guidewire and operator expert decreased fluoroscopy time.

3. TRA by non-hydrophilic guidewire and operator expert decreased procedural time.

4. TRA by non-hydrophilic guidewire and operator expert promoted the procedure safety.

5. These would contribute to the improvement and widely application of TRA.

\section{Abbreviations}

TFA: Trans femoral angiography; TRA: Transradial approach for coronary angiography.

\section{Competing interests}

The authors declare that they have no competing interests.

\section{Authors' contributions}

NW and XT participated in the design of this study, and they both performed the statistical analysis. JY and SL carried out the study, together with YS, collected important background information, and drafted the manuscript. XY, LZ and GT conceived of this study, and participated in the design and helped to draft the manuscript. All authors read and approved the final manuscript.

\section{Author details}

'Department of Cardiology, Beijing Anzhen Hospital, Capital Medical University, No.2, Anzhen Road, Beijing 100029, China. ${ }^{2}$ Department of Cardiology, Hangzhou Hospital (Hangzhou No.1 Municipal Hospital), Nanjing Medical University, Hangzhou, China.

Received: 30 August 2014 Accepted: 27 November 2014 Published online: 05 December 2014 


\section{References}

1. Nathan SRS: Radial versus femoral access for percutaneous coronary intervention: implications for vascular complications and bleeding. Curr Cardiol Rep 2012, 14:502-509.

2. Frangos Noble CDBE, Noble S: Transradial approach for coronary angiography and angioplasty: the gold standard. Rev Med Suisse 2011, 7:528-532.

3. Schussler JM: Effectiveness and safety of transradial artery access for cardiac catheterization. Proc (Bayl Univ Med Cent) 2011, 24:205-209.

4. Rodriguez-Leor OF-NE, Carrillo X, Mauri J, Rodriguez-Leor O, FernandezNofrerias E, Carrillo X, Mauri J, Oliete C, Rivas Mdel C, Bayes-Genis A: Transradial percutaneous coronary intervention in cardiogenic shock: a single-center experience. Am Heart J 2013, 165:280-285.

5. Jang JS, Jin HY, Seo JS, Yang TH, Kim DK, Kim DK, Kim DI, Cho Kl, Kim BH, Park YH, Je HG, Kim DS: The transradial versus the transfemoral approach for primary percutaneous coronary intervention in patients with acute myocardial infarction: a systematic review and meta-analysis. Euro Interv 2012, 8:501-510.

6. Shah B, Bangalore S, Feit F, Fernandez G, Coppola J, Attubato MJ, Slater J: Radiation exposure during coronary angiography via transradial or transfemoral approaches when performed by experienced operators. Am Heart J 2013, 165:286-292.

7. Yuan MK, Tsai DC, Chang SC, Yuan MC, Chang SJ, Chen HW, Leu HB: The risk of cataract associated with repeated head and neck CT studies: a nationwide population-based study. Am J Roentgenol 2013, 201:626-630.

8. Godino C, Maccagni D, Pavon AG, Viani G, Cappelletti A, Margonato A, Colombo A: Estimating incidence of organ cancer related to $\mathrm{PCl}$ radiation exposure in patients treated for acute and chronic total occlusions. J Invasive Cardiol 2013, 25:441-445.

9. Borghini ALGE, Picano E, Andreassi MG: Ionizing radiation and atherosclerosis: Current knowledge and future challenges. Atherosclerosis 2013, 230:40-47.

10. Andreassi MG, Cioppa A, Manfredi S, Palmieri C, Botto N, Picano E: Acute chromosomal DNA damage in humanlymphocytes after radiation exposure in invasive cardiovascular procedures. Eur Heart J 2007, 28:2195-2199.

11. Brix G, Berton M, Nekolla E, Lechel U, Schegerer A, Süselbeck T, Fink C: Cumulative radiation exposure and cancer risk of patients with ischemic heart diseases from diagnostic and therapeutic imaging procedures. Eur J Radiol 2013, 82:1926-1932.

12. Farman MTKN, Sial JA, Saghir T, Rizvi SN, Zaman KS: Comparison of fluoroscopy time during coronary angiography and interventions by radial and femoral routes- can we decrease the fluoroscopy time with increased experience? An observational study. Anadolu Kardiyol Derg 2011, 11:607-612.

13. Brasselet $C$, Blanpain T, Tassan-Mangina S, Deschildre A, Duval S, Vitry F, Gaillot-Petit N, Clément JP, Metz D: Comparison of operator radiation exposure with optimized radiation protection devices during coronary angiograms and ad hoc percutaneous coronary interventions by radial and femoral routes. Eur Heart J 2008, 29:63-70.

14. Lo TSRK, Chong AY, Bhatia G, Gunning M, Nolan J: Impact of access site selection and operator expertise on radiation exposure; a controlled prospective study. Am Heart J 2012, 164:455-461.

15. Barbeau GR: Radial loop and extreme vessel tortuosity in the transradial approach: advantage of hydrophilic-coated guidewires and catheters. Cardiovasc Interv 2003, 59:442-450.

16. McConnell EA: Performing Allen's test. Nursing 1997, 27:26

17. Varenne O, Jégou A, Cohen R, Empana JP, Salengro E, Ohanessian A Gaultier C, Allouch P, Walspurger S, Margot O, El Hallack A, Jouven X, Weber $S$, Spaulding C: Prevention of arterial spasm during percutaneous coronary interventions through radial artery: the SPASM study. Catheter Cardiovasc Interv 2006, 68:231-235.

18. Dominici M, Diletti R, Milici C, Bock C, Placanica A, D'Alessandro G, Arrivi A Italiani M, Buono E, Boschetti E: Operator exposure to x-ray in left and right radial access during percutaneous coronary procedures: OPERA randomised study. Heart 2013, 99:480-484.

19. Zhao Y, Ru L, Li J: Application of PTCA guidewire in abnormal assess of Transradial Coronary Procedures. Hebei Med J 2011, 33:2934-2935.

20. Sciahbasi A, Romagnoli E, Trani C, Burzotta F, Pendenza G, Tommasino A, Leone AM, Niccoli G, Porto I, Penco M: Evaluation of the "learning curve" for left and right radial approach during percutaneous coronary procedures. Am J Cardio/ 2011, 108:185-188.

21. Kristić ILJ: Radial artery spasm during transradial coronary procedures. J Invasive Cardiol 2011, 23:527-531.

22. Kiemeneij FFD, Slagboom T, Laarman G, van der Wieken R: Hydrophilic coating aids radial sheath withdrawal and reduces patient discomfort following transradial coronary intervention: a randomized double-blind comparison of coated and uncoated sheaths. Catheter Cardiovasc Interv 2003, 59:161-164.

23. Jia DA, Zhou YJ, Shi DM, Liu YY, Wang JL, Liu XL, Wang ZJ, Yang SW, Ge HL, Hu B, Yan ZX, Chen Y, Gao F, Jia DA, Zhou YJ, Shi DM, Liu YY, Wang JL, Liu $X L$, Wang ZJ, Yang SW, Ge HL, Hu B, Yan ZX, Chen Y, Gao F: Incidence and predictors of radial artery spasm during transradial coronary angiography and intervention. Chin Med J 2010, 123:843-847.

24. Chen CWLC, Lin TK, Lin CD: A simple and effective regimen for prevention of radial artery spasm during coronary catheterization. Cardiology 2006, 105:43-47.

25. Coppola J, Patel T, Kwan T, Sanghvi K, Srivastava S, Shah S, Staniloae C: Nitroglycerin, nitroprusside, or both, in preventing radial artery spasm during transradial artery catheterization. J Invasive Cardiol 2006, 18:155-158.

26. Goldsmit A, Kiemeneij F, Gilchrist IC, Kantor P, Kedev S, Kwan T, Dharma S, Valdivieso L, Wenstemberg B, Patel T: Radial artery spasm associated with transradial cardiovascular procedures: Results from the RAS registry. Catheter Cardiovasc Interv 2014, 83:E32-E36.

27. Koga S, Ikeda S, Futagawa K, Sonoda K, Yoshitake T, Miyahara Y, Kohno S: The use of a hydrophilic-coated catheter during transradial cardiac catheterization is associated with a low incidence of radial artery spasm. Int J Cardiol 2004, 96:255-258.

28. Sciahbasi A, Romagnoli E, Burzotta F, Trani C, Sarandrea A, Summaria F: Transradial approach (left vs right) and procedural times during percutaneous coronary procedures: TALENT study. Am Heart J 2011, 161:172-179.

29. Kawashima O, Endoh N, Terashima M, Ito Y, Abe S, Ootomo T, Ogata K, Honda H, Takizawa K, Miyazaki Y, Sugawara D, Komatsu M, Sawazi Y, Ozaki T, Uchimuro T, Meguro T, Isoyama S: Effectiveness of right or left radial approach for coronary angiography. Catheter Cardiovasc Interv 2004, 61:333-337.

30. Hamon M, Gomes S, Clergeau MR, Fradin S, Morello R, Hamon M: Risk of acute brain injury related to cerebral microembolism during cardiac catheterization performed by right upper limb arterial access. Stroke 2007, 38:2176-2179.

31. Pelliccia F, Trani C, Biondi-Zoccai GG, Nazzaro M: Comparison of the feasibility and effectiveness of transradial coronary angiography Via right versus left radial artery approaches (from the PREVAlL study). Am J Cardiol 2012, 110:771-775

32. Rao SV, Cohen MG, Kandzari DE, Bertrand OF, Gilchrist IC: The transradial approach to percutaneous coronary intervention: historical perspective, current concepts, and future directions. J Am Coll Cardiol 2010, 55:2187-2195.

\section{doi:10.1186/s13019-014-0194-5}

Cite this article as: Yang et al.: Impact of guidewire selection and operator expertise on radiation exposure in transradial angiography. Journal of Cardiothoracic Surgery 2014 9:194.

\section{Submit your next manuscript to BioMed Central and take full advantage of:}

- Convenient online submission

- Thorough peer review

- No space constraints or color figure charges

- Immediate publication on acceptance

- Inclusion in PubMed, CAS, Scopus and Google Scholar

- Research which is freely available for redistribution 